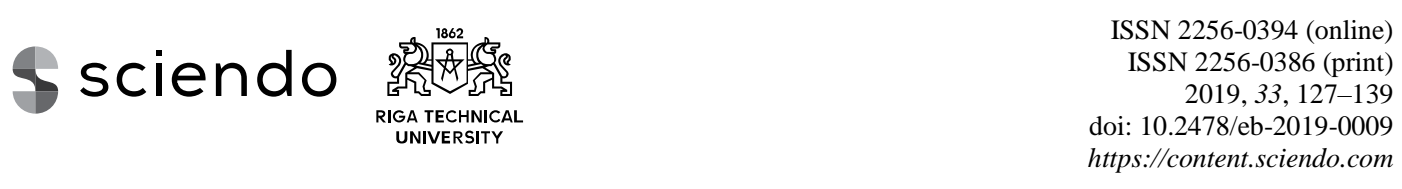

\title{
MODELLING SUPPORT MECHANISM IMPACT ON ELECTRIC VEHICLE REGISTRATION IN LATVIA
}

\author{
Gustavs GUDZUKS ${ }^{1}$, Sarma CAKULA ${ }^{2}$ \\ ${ }^{1,2}$ Vidzeme University of Applied Sciences, Valmiera, Latvia \\ Corresponding author's e-mail: Gustavs.Gudzuks@va.lv
}

\begin{abstract}
Globalization has led to an increased anthropological impact on the climate, and transport is one of the most greenhouse gas (GHG) intensive sectors that is facilitating it. Transport generated around 14 percent of global GHG emissions in 2010. Transport decarbonization is vital for limiting climate change, and electric vehicle (EV) is one of the solutions. EV prevalence in Latvia after Climate Financial Instrument (CCFI) funding has steadily increased and the average yearly EV growth has remained at 0.09 percent among newly registered light-duty passenger vehicles. The aim of this research is to model the impact of different direct and indirect support mechanisms on EV growth in Latvia taking into account the costs of the given support mechanisms. Accordingly, theoretical literature and research on vehicle decarbonization, EV support mechanisms, and barriers were analyzed. In order to obtain the data related to individual attitude towards EVs and their support policies a survey of different age groups was conducted. Based on the theoretical literature, a model was devised using STELLA software. The model was verified and validated. The results of the model indicate that until 2030 direct subsidies of at least 45 percent will have the largest impact on EV registration, while decreasing VAT by at least 9 percent is the most cost-effective option. The results regarding indirect support mechanisms show that free charging and development of charging infrastructure, as well as improvements to EV related technologies would increase EV registration. However, to ensure sustainable support to EVs it is advisable to combine direct incentives with indirect support mechanisms. Combining different policies lowers incentive costs and increases their efficiency.
\end{abstract}

Keywords: climate change, electric vehicles, sustainable transport, system dynamics modelling

JEL Classification: G40, Q40, Q54

\section{INTRODUCTION}

Transport is one of the most greenhouse gas (GHG) intensive sectors that was responsible for $27 \%$ of all GHG emissions in the European Union (EU) in 2016 (incl. international aviation and shipping) (EEA, 2017). In Latvia, transport produces $28 \%$ of all GHG emissions (Ministry of Environmental Protection and Regional Development, 2017). Transport is a direct contributor to global warming and air pollution, impacting human health and environment.

Many solutions have been proposed to counter global warming generated by the transportation sector, however only some have been developed into 
commercially available products. While hydrogen fuel cells, biofuels and natural gas promise to decrease GHG emissions, electric vehicles (EV) are leading the evolution of the transport sector providing hybrid and fully electric solutions. Developments in lithium battery technology have opened new possibilities for EVs, increasing their range, performance and practicability (Liebreich, 2017).

Currently, there is a broad range of EVs available from major car producers (e.g. BMW, Volkswagen, Nissan, etc.), as well as from new EV manufacturers such as Tesla. Experts predict that market penetration and EV model range will increase as more car manufacturers introduce hybrid and full EVs (Griffin, 2017; Vaughn, 2017).

EVs have also received widespread support from governmental institutions providing direct and indirect incentives in the form of purchase subsidies, tax cuts, free charging, free parking, access to public transport lanes and access to emission control zones (e.g. city centers). Latvia is no exception and has introduced exemption from road tax (Cabinet of Ministers Amendments to the Law on the Vehicle Operation Tax and Company Car Tax, of 23 November 2016), free parking in the capital city Riga, access to public transport lanes (Cabinet Regulations No 279, of 02 June 2015), free charging at some charging stations, as well as direct subsidies (Cabinet Regulations No 78, of 04 February 2014).

As EVs have large potential for decarbonizing the transport sector, it is of a great importance to test and develop solutions for increase of the number of EVs in Latvia. Current experience shows that certain types of EV support mechanisms have worked exceptionally well, with direct subsidies from $55-85 \%$ of the EV price increasing the total EV number by 174 vehicles (Zauers, 2016).

Decreasing GHG emissions is not only a national goal, but also global and regional. With the signing of Paris Agreement in 2015, countries, including the EU, have set their own climate goals. The EU has a strict renewable energy (RES) goal, which dictates $10 \%$ RES target for the Latvian transport sector until 2020. However, the RES directive (EU Directive 2009/28/EC) provides additional benefits for the countries that achieve GHG cuts through transport electrification (coefficient of five (5) is applied to RES sourced electricity used in transport).

EVs in Latvia have been researched in a few studies, mostly carried out by Riga Technical University. In 2015, a survey of EV integration into municipalities was conducted (Barisa, Rosa, \& Kisele, 2015; Rošā, Blumberga, \& Blumberga, 2015). In 2016, Aiga Barisa modeled development paths of different low-carbon modes of transport in Latvia by using system dynamics modeling approach and survey data (Barisa, 2016). Most researchers have concluded that the main barriers for EV market penetration in Latvia were limited network of charging stations, maturity of EV technology, limited information and high up-front costs. Unless significant subsidies are provided for the purchase of EVs, there is limited possibility for the growth of the EV market in Latvia.

This paper focuses on the approaches that ensure increased EV market penetration. For this reason, four scenarios involving direct and indirect support mechanisms are modeled, simulating 11-year EV market development. To test each support mechanism, sub-scenarios are devised, and the results are analyzed. 
A base scenario is developed in view of the current EV market trends. Additionally, EV price decrease impact is tested. The impact of direct subsidies and three unspecified indirect support mechanisms are considered. After base scenario testing, the model is devised, integrating survey results of 402 respondents. At first, direct support mechanisms are tested, these involve gradual increase of the level of direct subsidies from $35 \%$ to $45 \%$ in five percent increments. After that applicable value added tax (VAT) rate is decreased for EVs and the results are observed. The last scenario tested in the model determines the efficiency of indirect support mechanisms. The following sub-scenarios are tested: increase of fossil fuel price, EV infrastructure development and maturation of technology, free parking, free charging, and biennial technical inspections (opposite to annual).

Furthermore, several combinations of support mechanisms are tested, like fuel price increase with subsidies, VAT decrease and fuel price increase.

\section{THEORETICAL FRAMEWORK}

\subsection{EV support mechanisms}

International Council on Clean Transportation (ICCT) divides EV support mechanisms into two main categories: subsidies (direct payments to EV buyers or income tax refunds) and tax deduction (VAT reduction or road tax decrease) (Yang, Slowik, Lutsey, \& Searle, 2016:4-16). However, there are other non-financial EV support mechanisms, e.g. permission to use public transport lanes, free-parking, charging network development (Infometrics, 2015:2). Some countries with welldeveloped automotive industry provide also incentives for the industry rather than consumer. Dunnan Liu and Bowen Xiao divide EV support mechanisms into two groups (Liu, Xiao, 2018:10-11):

- Direct policies - support mechanisms that are directly aimed at EV market share increase (e.g. subsidies to consumers and industry, funding for charging stations);

- Indirect policies - energy and environmental policies that do not directly influence EV sector but provide benefits to it.

Within this paper, non-financial policies, such as free-parking, decreased taxes and other mechanisms will also be considered as indirect policies.

Another aspect of EV support policies are their availability to different groups. Some incentives are aimed at the industry (Wesseling, 2016), while others - at the institutions or private citizens (Yang et al., 2016:4-16). This paper concentrates on the share of private citizens in the market, since there have been subsidies provided to businesses, institutions and municipalities in Latvia in the past.

\subsection{EV support in Latvia}

In 2016, Latvia introduced exemption from road tax (Cabinet of Ministers Amendments to the Law on the Vehicle Operation Tax and Company Car Tax, 23.11.2016.), free parking in Riga, access to public transport lanes (Cabinet Regulations No 279, of 02 June 2015), free charging at some charging stations and direct subsidies (Cabinet Regulations No 78, of 04 February 2014). Additionally, 
Latvia has invested the EU funding in the development of charging network throughout Latvia, therefore allowing uninterrupted driving with EVs. Currently, there are 72 operational charging stations but until 2021 there will be 150 charging stations operating in Latvia (Road Traffic Safety Directorate, 2018).

In 2017, battery EV and hybrids constituted $1.4 \%$ of the new light passenger vehicle market in the EU. Situation in 2018 was similar. However, in the EU countries with gross domestic product (GDP) under 18000 EUR per capita, the EV market share was closer to zero and in a half of the EU countries EV did not cross the threshold of $0.75 \%$. Data shows that $85 \%$ of the EVs are sold in six developed EU countries. Data also shows that hybrid vehicles have a higher niche than battery EVs (ICCT, 2018:6-7).

There is a strong divide between Western and Eastern European countries, as well as Northern and Southern (ACEA, 2018). Outside the EU, only Norway showed better results with EVs achieving $39 \%$ of the market share (ICCT, 2018:67). Similar situation is observed concerning the charging infrastructure, as $76 \%$ of the charging stations are located in the Netherlands, United Kingdom, Germany and France (ACEA, 2018).

\subsection{Barriers}

Although the use of $\mathrm{EV}$ and hybrid vehicles provides benefits to the environment and health, electrification of the transport sector has been slow. One of the most important aspects that is limiting EV dissemination is technological maturity and price. EV technology is dependent on powerful battery systems, which currently cost more than the development of fuel systems for internal combustion cars. Increased drivetrain costs also impact consumer prices and the appeal of EV technology. Furthermore, technological maturity of EVs negatively affects their usability (driving range), reliability and maintenance (lack of trained specialists, spare parts, etc.). There is also lack of secondary (used EV) market for EVs (Infometrics, 2015; Noori, \& Tatari, 2016). Nevertheless, it is important that any of the EV support mechanisms are funded in the long term (Yang et al., 2016).

Large car manufacturers also are reluctant to invest in unproven and highly costly technologies with limited return on investment. Lack of EV model range negatively impacts technology appeal and support to technology pioneers (Sierzchula, Bakker, Maat, \& van Wee, 2014:184-185).

Dae-Chul Janga, Bosung Kimb and Su-Yol Lee emphasize the cooperation between industry, institutions and charging infrastructure developers to align and standardize EV technology deployment (Janga, Kimb, \& Lee, 2018).

Hanna L. Breetz and Deborah Salon believe that in the foreseeable future, EVs will be dependent on support, since the EV market is slow to develop. In order to see consumer prices decrease, EV technology should become also more widespread within the industry. Breetz and Salon emphasize that EVs should become cheaper, otherwise, with high purchase price, there is limited economic benefit from EVs. Currently, hybrids provide good fuel efficiency, are environmentally friendly and have a lower up-front price and break even faster than battery EVs. On average, an EV (Nissan Leaf) has to travel $217000 \mathrm{~km}$ per year compared to a hybrid (Toyota Prius) to justify the investment (Breetz, \& Salon, 2018). Hybrids also have played 
a more significant role in the EU light duty passenger vehicle market, taking up to $4.5 \%$ of the market share of new passenger vehicles (ICCT, 2018:6-7).

EV technological limits are not the only barriers to the EV market growth. Consumer perception of the EV technology and limited knowledge have restricted the prevalence of EVs. There is certain skepticism regarding the EV driving range and usability (Lane et al., 2018). 2012 research showed that on average commuters in Europe drive from $40 \mathrm{~km}$ (UK) to $80 \mathrm{~km}$ (Poland) daily and rest for $16 \mathrm{~h}$, which is well in the battery range of the existing EVs (Pasaoglu et al., 2012:84). Researchers connect such behavior to bounded rationality, which forces consumers look at the EV procurement price alone, not the lifecycle costs (Sierzchula et al., 2014:184-185).

Consumer attitude is one of the most important aspects of the EV market growth. Research about Austrian EV market showed that the regions with EV support policies and charging infrastructure favored EVs more than the regions without infrastructure and incentives. At the current stage it is more beneficial to promote EVs to city dwellers than rural and suburban residents who have limited access to charging infrastructure and encounter EVs less frequently (Priessnera, Sposatoa, \& Hampl, 2018).

\section{SIMULATION MODELLING}

For the needs of the current research, a system dynamics model was developed on ISEE Systems Stella 9.0.1. software. Stock and flow approach was used for the model to create nine modules, each responsible for a certain aspect of the EV market in Latvia:

- EV price calculation (Fig. 1.);

- Internal combustion vehicle price calculation;

- EV number calculation module;

- Internal combustion vehicle number calculation;

- Cost of support mechanism calculation;

- EV acquisition coefficient calculation within age groups (three separate modules);

- Combined EV acquisition coefficient calculation;

- EV lifecycle cost calculation;

- Internal combustion vehicle lifecycle cost calculation. 


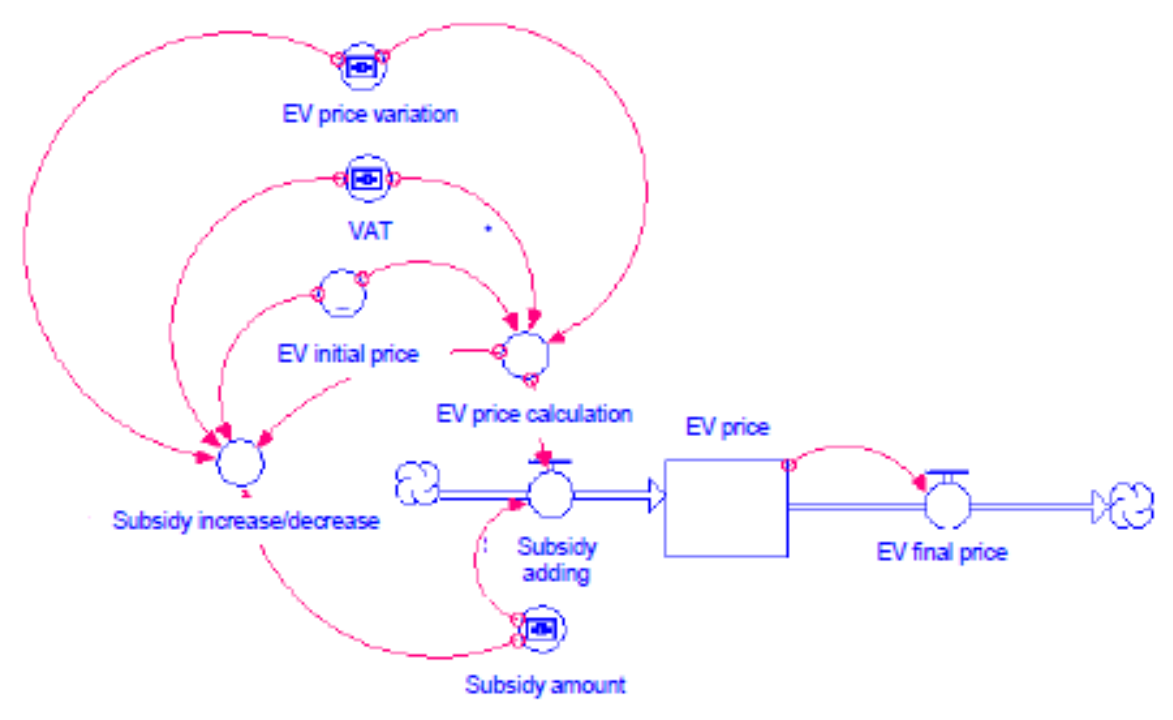

Fig. 1. EV price calculation module.

\subsection{Verification}

The model was verified performing manual check of each module's equations and output consistency with the input, as well as general logic of the model.

Extensive calculations were made to confirm that each module provides reliable and realistic data.

\subsection{Validation}

Validation was performed by a sector expert from the Ministry of Environmental Protection and Regional Development of the Republic of Latvia. The expert has extensively worked on the EV policy in Latvia and was responsible for drafting legislation for direct subsidies under the Climate Financial Instrument (CCFI) for municipalities and businesses. Additionally, the expert has been working with the researchers developing GHG models for the Latvian government.

The expert provided advice on improving the reliability and credibility of the model. Furthermore, the expert made suggestions on expanding the model, including economic aspects of the EV market.

\section{METHODOLOGY}

Primary data for the research were obtained through a survey of 402 respondents in three age groups: 18-25, 26-35 and 36-45. The survey included questions related to respondent attitude towards EVs, as well as their preferred support mechanisms and the preferred level of intensity. Most respondents were urban residents, while only few came from rural regions or suburbs.

In total 15 questions were asked to the respondents. The respondents had to evaluate different EV support mechanisms, the impact of support mechanisms on 
their choice of the means of transportation, the respondents were also asked to set values for the preferred amount of support.

Secondary data were obtained from other research papers (Plotz, Gnann, \& Sprei, 2017), Road Traffic Safety Directorate (2018) and Central Statistics Bureau (2016). Secondary data included information on the average mileage of cars in Latvia, registration data (number of cars, EVs, etc.), differences in registration number over years, de-registered cars, average fuel consumption for diesel cars, average consumption of electricity for EVs, average purchase price of fossil vehicles and EVs.

The model compared EVs to diesel cars that are one of the most efficient internal combustion solutions available currently on the market and are eagerly used in Latvia.

Primary data were processed using PSPP. Firstly, the data were ranked and afterwards data distribution, average and median values were obtained.

Secondary data were analyzed to obtain distribution. Some data were analyzed to obtain average values or yearly increase.

Distribution of data was obtained using Anderson-Darling, KolmogorovSmirnov and Chi-square tests.

Most results of the distribution tests corresponded or were close to normal distribution, which allowed the use of mean values for the creation of coefficient used in the model.

\section{RESULTS}

In order to model the EV market development in Latvia until 2030, four scenarios were devised:

- Base scenario - includes secondary data available from other researches (Plotz, Gnann, \& Sprei, 2017), Road Traffic Safety Directorate (2018) and Central Statistics Bureau (2016) and simulates the EV market development based on the existing pattern of EV registration in Latvia with an average increase of newly registered light-duty passenger vehicles at $0.09 \%$ and existing support mechanisms.

- Base scenario with additional support mechanisms - direct subsidies of $45 \%$ and three unspecified indirect incentives are introduced within the base scenario.

- Direct support mechanisms scenario across age groups - three levels of subsidies $(35 \%, 40 \%, 45 \%)$ and a VAT reduction to $12 \%$ (instead of $21 \%)$ is tested.

- Indirect support mechanism scenario across age groups - fossil fuel price increase (assumed to be 1.42 EUR/l, but not checked during survey), infrastructure and technology development, free-parking throughout Latvia, free-charging, biennial technical inspection coefficients are introduced in the simulation. 


\section{Base scenario}

In the base scenario with existing support mechanisms, EV number will increase by 541 vehicles by 2030 . However, decreasing the cost of EVs by $40 \%$ would increase the EV number by 1370 EVs.

\section{Base scenario with additional support mechanisms}

Two sub-scenarios are modeled based on the coefficients provided in a research on the European EV market (Plotz, Gnann, \& Sprei, 2017) modeled, one with direct subsidies of $45 \%$ and one with three additional non-specified indirect incentives.

Subsidies in the base scenario increase the overall number of EVs by 1713 vehicles over an 11-year period costing 44976121 EUR.

Three indirect incentives increase the overall number of EVs by 1103 vehicles. However, the model cannot calculate the cost of indirect incentives in the base scenario.

\section{Direct support mechanisms scenario across age groups}

At first, direct subsidies of $35 \%$ for the purchase of EV were tested. As only the age group 18-25 was responsive to this level of subsidies, the overall EV number increased by 270 vehicles, costing 11290854 EUR.

Increasing the subsidies level to $40 \%$ increased the overall number of registered EVs by 811 vehicles at the cost of 19441775 EUR.

Increasing the level of subsidies further until $45 \%$ allows involving the age group 36-45 and this increases the overall number of EVs by 1087 vehicles. Until 2030, the cost of subsidies increases to 29130404 EUR.

Halving the VAT or reducing it to the $12 \%$ level as compared to the current VAT level in Latvia of $21 \%$ increases the number of registered EVs by 951 vehicles and costs 5342187 EUR (money not received in the state budget), which is a more economical approach than subsidies.

This proves that subsidies and early incentives are vital to the technology pioneers that adapt unproven early-stage solutions. As cited by the International Council on Clean Transportation (ICCT) and other authors, direct subsidies like tax reduction and direct payments are the most effective incentives, as they decrease upfront investments of potential EV users and make EVs more appealing (Yang et al., 2016:4-16).

\section{Indirect support mechanism scenario across age groups}

First of all, fossil fuel price increase is tested. 1.42 EUR/l is established as the critical margin that triggers increase of the EV market share. However, the survey did not include a question regarding the critical fuel price but rather asked if fuel prices would make EVs more appealing.

Fuel price increase is not a significant motivator to acquire an $\mathrm{EV}$ as it provides only additional 303 vehicles over the 11-year period compared to the base scenario. As noted by the authors, fuel price increase alone is not enough to garner interest 
from consumers. This has been evident during the last fuel price spikes that occurred from 2007-2008 and from 2011-2014 (Lane et al., 2018).

Fuel price increase can be combined with other incentives, allowing higher gain in EV numbers and also tax revenues. Combining $45 \%$ subsidies with increased fuel prices will generate additional $1389 \mathrm{EVs}$ over an 11-year period. Increase in fuel prices can be both natural (conditioned by global economy trends) and artificial (stimulated by changes in excess tax rates). This allows providing funding for subsidies - relocating wealth to environmentally sound solutions (Sierzchula et al., 2014).

Another possibility is to combine lower VAT with increased fuel price, and that will increase the overall EV number by 1254 vehicles.

EV technology and infrastructure development had the largest impact on the age group 36-45, increasing EV number by 209 vehicles. In all age groups, the development of EV technology and infrastructure will allow increasing the overall EV numbers by 492 vehicles.

As respondents and authors have indicated, one of the main barriers to wide use of EVs is their limited range, expensive maintenance, technological maturity and lack of infrastructure, as well as higher purchasing prices (Infometrics, 2015; ACEA, 2018). Typically, regions with denser charging network will have higher numbers of EVs. Nevertheless, it is important that the network is synchronized with the EV production standards and allows charging of more EV models (Priessnera, Sposatoa, \& Hampl, 2018; Janga, Kimb, \& Lee, 2018).

Free-parking in the entire territory of Latvia would provide only minor increase in EV numbers - 95 vehicles over base scenario in the age group 26-35. In all age groups, free-parking would generate additional 224 EVs over 11-year period. Estimating the price of free-parking is complicated, as the price depends on municipality and economic situation in the city.

Free-charging would leave the largest benefit on the age group 26-35, increasing EV numbers by 195 vehicles. In all age groups free charging would add additional 489 EVs. Free-charging is also a relatively cheap incentive. However, over a longer time period, with increasing EV numbers, free-charging will progressively cost more.

It is also important to note that the source of the electricity should be RES, otherwise the benefits from EVs would be limited.

Biennial technical inspections for EVs are seen as a benefit by younger generation (18-25), thus increasing EV number by 70 vehicles. In all age groups biennial technical inspection would increase the overall EV number by 173 vehicles. Similarly, as with other indirect incentives, it would be beneficial to combine biennial technical inspection with other support mechanisms.

\section{Comparison of support policies impact on EV lifecycle costs}

The mode allows simplified calculation of EV and internal combustion vehicle lifecycle costs. Even in the base scenario EVs cost less to maintain. Due to the limited complexity of the model's lifecycle module, the costs are only indicative. Nevertheless, the model shows that EV maintenance and charging costs over the vehicle's lifetime are significantly lower. But as the authors indicate, rarely do car 
buyers consider lifecycle costs (i.e. fuel, maintenance, taxes, etc.). Most potential buyers of EVs are discouraged by higher initial costs. Such behavior is closely related to bounded rationality and is not limited to EVs. Other environmentally friendly products suffer from similar customer behavior (Lane et al., 2018; Pasaoglu et al., 2012; Sierzchula et al., 2014).

Introduction of free-charging would decrease the average annual electricity costs from around 600 EUR to 200 EUR (based on 2018 electricity prices in Latvia). However, as seen previously, free charging has limited effect on the number of registered EVs over an 11-year period (Yang et al., 2016).

Introducing direct subsidies for EV procurement of $45 \%$ would achieve price parity with internal combustion cars. If fossil fuel prices are raised in combination with direct subsidies, it is possible to ensure longevity of subsidies and decrease appeal of internal combustion cars (Yang et al., 2016).

\section{CONCLUSIONS}

Market penetration of EVs in Latvia is limited due to socio-economic reasons and limited support mechanisms. EV technology currently is too expensive for the low-income level of an average individual in Latvia. Base scenario shows that without additional support mechanisms the number of registered EVs in Latvia would increase by 541 by 2030 from 312 EV registered in 2017.

With additional three indirect support policies (e.g. free parking, biennial technical inspection, free charging) the EV number would increase by 1103 vehicles, however considering different support policy costs this would not be the most economical approach.

Use of the survey data to test different indirect support mechanisms has shown that technology and infrastructure development would provide best results increasing the number of registered EVs by 492 vehicles. Similar results also predict free charging, increasing the number of registered EVs by 489 vehicles.

While technology development cannot be directly impacted by countries and infrastructure development is directly linked to charging technology prices, free charging can and has been provided as an incentive by state actors.

Free charging has its downsides. If cheap renewable electricity is not available, then the benefits from free charging or EV technology in general will be limited. Either the costs will be too great or environmental benefits from reduced GHG will not be achieved.

Free parking in the entire territory of Latvia has a limited effect on EV numbers, increasing the quantity of registered EVs by 224 vehicles by 2030. It is, however, very hard to analyze the cost of free-parking as different municipalities value their parking space differently. Additionally, the increase in the economic activity of a city will automatically increase the value of parking space.

Biennial technical inspection for EVs has a low impact, increasing the number of registered EVs by 173 vehicles.

Direct subsidies for the acquisition of EVs have a large impact on the overall EV numbers. $35 \%$ subsidies would increase the registered EVs by 270 vehicles, $40 \%$ - by $541 ; 45 \%$ - by 1087 . Every $5 \%$ increase in subsidies doubles the 
number of registered EVs. Although direct subsidies are effective, they cost much more than other incentives - 29130404 EUR over the 11-year period (at $45 \%$ intensity).

In the base scenario, direct subsidies of $45 \%$ provide additional $1713 \mathrm{EV}$ s over the 11-year period. However, in the scenario that takes into consideration survey data, $45 \%$ subsidies increase the overall EV number by 1087 vehicles over the same period.

From direct incentives, VAT reduction is one of the cost-effective solutions. Halving VAT (to $12 \%$ from $21 \%$ ) in Latvia would increase EV numbers by 951 vehicles while costing 5342187 EUR.

It is advised to combine and supplement direct incentives with indirect support mechanisms to attain higher EV market penetration with lower direct costs. Furthermore, some incentives can redistribute funds to increase appeal of EVs. For instance, increasing fuel prices through higher excise tax may provide necessary funding for direct subsidies.

Increasing fuel prices and halving VAT would generate additional 1795 EVs over the base scenario. While combining higher fuel costs with direct subsidies would increase the overall EV number by 1930 vehicles.

Cooperation between institutions and industry is imperative to achieve the best results from any direct and indirect support mechanisms. Approaches like Strategic Niche Management or Transition Management should be used to achieve the best results.

In the long term, EV market penetration will be more dependent on decreasing technology prices, improved manufacturing of parts, especially batteries, and availability of charging infrastructure that might lead to faster price parity of EVs and internal combustion cars. Base scenario anticipates that EV price decrease by $40 \%$ would add additional 1370 EVs until 2030. However, in order for the EV market to develop and mature, initial subsidies and indirect incentives are required. Over time, as the EV market matures, subsidies and incentives should be decreased.

\section{REFERENCES}

Barisa, A. (2016.) Modelling Transition Policies to a Low-Carbon Road Transport in Latvia by 2030 Dissertation. Riga Technical University, Faculty of Power and Electrical Engineering, Institute of Energy Systems and Environment. Riga: RTU Press 2016. Retrieved from https://ortus.rtu.lv/science/en/publications/22594/attachments/1108

Barisa, A., Rosa, M., Kisele, A. (2015). Introducing Electric Mobility in Latvian Municipalities: Results of a Survey. Energy Procedia, 95, 50-57. https://doi.org/10.1016/j.egypro.2016.09.015

Breetz, H. L., \& Salon, D. (2018). Do Electric Vehicles Need Subsidies? Ownership Costs for Conventional, Hybrid, and Electric Vehicles in 14 U.S. cities. Energy Policy, 120, 238-249. https://doi.org/10.1016/j.enpol.2018.05.038

The Cabinet of Ministers of the Republic of Latvia. (2016). Amendments to the Law on the Vehicle Operation Tax and Company Car Tax (23.11.2016.) Latvijas Véstnesis, 241 (5813), 10.12.2016. Retrieved from https://likumi.lv/ta/id/287291-grozijumi-transportlidzekla-ekspluatacijas-nodokla-un-uznemumu-vieglotransportlidzeklu-nodokla-likuma

The Cabinet of Ministers of the Republic of Latvia (2015). Cabinet regulation No. 279 (02.06.2015). Road traffic regulations. Retrieved from https://likumi.lv/ta/en/id/274865-road-traffic-regulations

The Cabinet of Ministers of the Republic of Latvia. (2014). Cabinet regulation Nr. 78 (04.02.2014). Climate change financial instrument project competition "GHG emission reduction in transport sector - support to $\mathrm{EV}$ and charging infrastructure development" provision. 
Central Statistics Bureau of Latvia (2016). Average Fuel Consumption per $100 \mathrm{~km}$ (l). Retrieved from https://www.csb.gov.lv/en/statistics/statistics-by-theme/environment-energy/energyconsumption/tables/epm450/average-fuel-consumption-100-km-1

The European Parliament and the Council (2009). Directive 2009/28/EC of 23 April 2009 on the promotion of the use of energy from renewable sources and amending and subsequently repealing Directives 2001/77/EC and 2003/30/EC. Retrieved from https://eur-lex.europa.eu/legalcontent/EN/TXT/PDF/?uri=CELEX:32009L0028\&from=EN

EEA. (2017). Greenhouse Gas Emissions from Transport. Retrieved from https://www.eea.europa.eu/data-andmaps/indicators/transport-emissions-of-greenhouse-gases/transport-emissions-of-greenhouse-gases-11

European Automobile Manufacturers' Association (ACEA). (2018). Overview on Tax Incentives for Electric Vehicles in the EU. ACEA. Retrieved from https://www.acea.be/uploads/publications/EV_incentives_overview_2018.pdf

Griffin, A. (2017). Volvo to Make Only Electric Cars from 2019, Marking the end of the Petrol Engine. Independent. Retrieved from http://www.independent.co.uk/life-style/gadgets-and-tech/news/volvo-carelectric-hybrid-vehicle-petrol-diesel-combustion-engine-a7824316.html

ICCT. (2018). European Vehicle Market Statistics. Pocketbook 2018/19. ICCT. pp. 6-7. Available: https://www.theicct.org/sites/default/files/publications/ICCT Pocketbook 2018 Final 20181205.pdf

Infometrics (2015). A Model for Projecting the Uptake of Electric Vehicles for Ministry of Transport. Retrieved

from https://www.google.com/url?sa=t\&rct=j\&q=\&esrc=s\&source=web\&cd=10\&cad=rja\&uact=8\&ved=2ahU KEwie8s2I4rvfAhVGDywKHVsVARYQFjAJegQICRAC\&url=https\%3A\%2F\%2Fwww.transport.govt. nz\%2Fassets\%2FUploads\%2FResearch\%2FDocuments\%2F2015-Transport-Knowledge-

Presentations\%2FElectric-vehicles-future-cost-and-uptake-scenarios-Bronwyn-Lauten-Ministry-ofTransport.pdf\&usg=AOvVaw1reboel6osNwowD83Tqpaa

Janga, D-C., Kim, B., \& Lee, S-Y. (2018). A Two-Sided Market Platform Analysis for the Electric Vehicle T Adoption: Firm Strategies and Policy Design. Transportation Research Part D: Transport and Environment, 62, 646-658. https://doi.org/10.1016/j.trd.2018.02.002

Lane, B.W., Dumortier, J., Carley, S., Siddiki, S., Clark-Sutton, K., Graham, J.D. (2018). All Plug-In Electric Vehicles are not the Same: Predictors of Preference for a Plug-In Hybrid Versus a Battery-Electric Vehicle. Transportation Research Part D: Transport and Environment, 65, 1-13. https://doi.org/10.1016/j.trd.2018.07.019

Liebreich, M. (2017). Breaking Clean. London Summit 2017. Bloomberg New Energy Finance. Retrieved from https://data.bloomberglp.com/bnef/sites/14/2017/09/BNEF-Summit-London-2017-Michael-LiebreichState-of-the-Industry.pdf

Liu, D., \& Xiao, B. (2018). Exploring the Development of Electric Vehicles under Policy Incentives: A Scenario-Based System Dynamics Model. Energy Policy, 120, 8-23. https://doi.org/10.1016/j.enpol.2018.04.073

Ministry of Environmental Protection and Regional development of Latvia. (2017). Report on Climate Change Financial Instrument Operation in 2016. Retrieved from http://www.varam.gov.lv/in_site/tools/download.php?file=files/text/KPFI/lik//VARAMZino_KPFI_darbi ba_2016.pdf

Noori, M., \& Tatari, O. (2016). Development of an Agent-Based Model for Regional Market Penetration Projections of Electric Vehicles in the United States. Energy, 96, 215-230. https://doi.org/10.1016/j.energy.2015.12.018

Pasaoglu, G., Fiorello, D., Martino, A., Scarcella, G., Alemanno, A., Zubaryeva, A., Thiel, C. (2012). Driving and Parking Patterns of European Car Drivers - a Mobility Survey. Joint Research Centre. Institute for Institute for Energy and Transport. Luxembourg: Publications Office of the European Union. Retrieved from a7a136dfd187.0001.02/DOC_1 http://publications.europa.eu/resource/cellar/2d5d968f-4f4c-4ee0-82e2-

Plotz, P., Gnann, T., \& Sprei, F. (2017). What are the Effects of Incentives on Electric Vehicle Sales in Europe? Fraunhofer Institute for Systems and Innovation Research ISI, Karlsruhe, Germany. Retrieved 26.09.2018 from https://www.eceee.org/library/conference_proceedings/eceee_Summer_Studies/2017/4-mobilitytransport-and-smart-and-sustainable-cities/what-are-the-effects-of-incentives-on-plug-in-electric-vehiclesales-in-europe/2017/4-188-17_Ploetz.pdf/

Priessner, A., Sposato, R., \& Hampl, N. (2018). Predictors of Electric Vehicle Adoption: An Analysis of Potential Electric $\mathrm{T}$ Vehicle Drivers in Austria. Energy Policy, 122, 701-714. https://doi.org/10.1016/j.enpol.2018.07.058

Road Traffic Safety Directorate. (2018). Press release: EV charging station network becomes operational. Retrieved from https://www.csdd.lv/jaunumi/darbu-uzsak-elektromobilu-atras-uzlades-staciju-tikls

Rošā, M., Blumberga, A., \& Blumberga, D. (2015). Modelling Sustainable Road Transport Strategies in Latvia. International Congress on Energy and Environment Engineering and Management: Extended Abstracts Book, France, Paris, 22-24 July, 2015. 
Sierzchula, W., Bakker, S., Maat, K., \& van Wee, B. (2014). The Influence of Financial Incentives and other Socio-Economic Factors on Electric Vehicle Adoption. Energy Policy, 68, 183-194. https://doi.org/10.1016/j.enpol.2014.01.043

Vaughn, A. (2017). Jaguar Land Rover to Make Only Electric or Hybrid Cars from 2020. The Guardian. Retrieved 11.01.2018 from https://www.theguardian.com/business/2017/sep/07/jaguar-land-roverelectric-hybrid-cars-2020

Wesseling, J. H. (2016). Explaining Variance in National Electric Vehicle Policies. Environmental Innovation and Societal Transitions, 21, 28-38. https://doi.org/10.1016/j.eist.2016.03.001

Yang, Z., Slowik, P., Lutsey, N., \& Searle, S. (2016). Principles for Effective Electric Vehicle Incentive Design. USA: International Council on Clean Transportation. White paper. Retrieved from https://www.theicct.org/sites/default/files/publications/ICCT_IZEV-incentives-comp_201606.pdf

Zauers, A. (2016). EVs to Latvia are Coming Slowly and Leisurely (in Latvian). Diena. Retrieved from https://www.diena.lv/raksts/izklaide/tehnologijas/elektromobili-latvija-ienak-leni-un-nesteidzigi14160312

\section{AUTHORS’ SHORT BIOGRAPHIES}

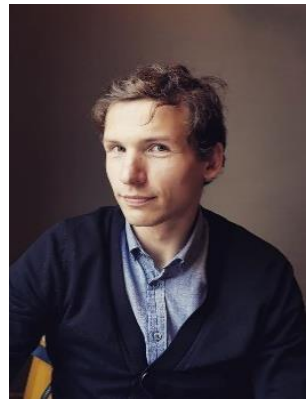

Gustavs Gudzuks has received a Master Degree from Vidzeme University of Applied Sciences in sociotechnical modelling (2019) and a Master Degree from the University of Latvia in political science (2017). He is currently planning to enrol in the Doctoral studies in sociotechnical modelling at the Vidzeme University of Applied Sciences. He specializes in environmental policy research with an emphasis on climate change. He has researched climate change policy barriers in Latvia. His current interests are related to mobility and dissemination of electric vehicles. He previously worked as a senior expert for the Ministry of Environmental Protection and Regional Development of the Republic of Latvia.

E-mail: Gustavs.Gudzuks@va.lv

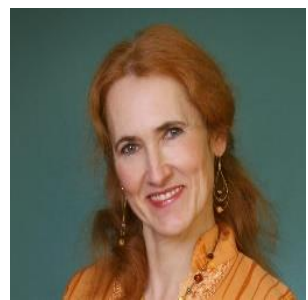

Sarma Cakula was born on $13^{\text {th }}$ December 1960 in Latvia, she graduated with distinction from Latvia University Department of Physics and Mathematics in 1984 and obtained Ph.D. in 2002. She started to work in Vidzeme University of Applied Sciences in 1996 as a network administrator. After that she was a director of a professional Bachelor program "Information Technology (IT)" and the Dean of the Faculty of Engineering of Vidzeme University of Applied Sciences, Latvia. She is a Professor of Information Technologies at the Faculty of Engineering and a researcher in at Socio-Technical Systems Engineering Institute. She also manages some European fund projects. She is a member of the International E-Learning Association (IELA), Latvian Information and Communication Technology Association (LIKTA) and the University Professors' Association of Latvia (LAPA). She has more than 60 scientific publications since 2001 in the field of information technologies and pedagogy, most of them in the field of e-learning.

E-mail: sarma.cakula@va.lv 